\title{
Compensatory Usage of the Internet: The Case of Mukbang Watching on YouTube
}

\author{
Kagan Kircaburun ${ }^{1,2} \bowtie$, Sabah Balta ${ }^{3}$, Emrah Emirtekin $^{4}$, Şule Betül Tosuntaş ${ }^{5}$, \\ Zsolt Demetrovics ${ }^{6}$, and Mark D. Griffiths ${ }^{1}$ \\ ${ }^{1}$ International Gaming Research Unit, Psychology Department, Nottingham Trent University, Nottingham, UK \\ ${ }^{2}$ Educational Sciences Department, Duzce University, Duzce, Turkey \\ ${ }^{3}$ School of Applied Sciences, Yaşar University, İzmir, Turkey \\ ${ }^{4}$ The Centre for Open and Distance Learning, Yaşar University, İzmir, Turkey \\ ${ }^{5}$ Educational Sciences Department, Uludağ University, Bursa, Turkey \\ ${ }^{6}$ Institute of Psychology, ELTE Eötvös Loránd University, Budapest, Hungary
}

Objective Accumulating empirical research has emphasized that a wide range of online activities-such as using social networking sites-can be performed in order to compensate unattained needs or to cope with negative affect and psychopathological symptoms. Although the correlates of problematic social networking use have been extensively investigated, less is known about problematic YouTube use (PYU), an umbrella term grouping a number of different activities (e.g., viewing of online video games, watching specific YouTube channels). Furthermore, nothing is known concerning increasingly popular and distinct YouTube-related activities such as mukbang watching (i.e., watching livestream "eating broadcasts" where someone eats various foods in front of the camera while interacting with viewers). The aim of the present study was to examine the mediating role of problematic mukbang watching (PMW) on the relationships between depression and loneliness with PYU.

Methods An online survey that comprised assessment tools for aforementioned variables was administered to 217 mukbang viewers (mean age $=20.58$ years, range $18-33$ years).

Results Results indicated that PMW was positively related to loneliness and PYU. Depression was positively and directly associated with PYU but was not associated with PMW.

Conclusion Further research is required to better understand the psychological processes underlying problematic mukbang watching and its association with other mental health conditions (e.g., addictive disorders, eating disorders).

Psychiatry Investig 2021;18(4):269-276

Key Words Problematic YouTube use, Mukbang, Problematic mukbang watching, Loneliness, Internet use, Compensatory usage of internet.

\section{INTRODUCTION}

YouTube allows its users to create, share, view, like, dislike, and comment on content that concerns various topics including movies, video clips, videogames, sports, food shows, and other different subjects that interest and entertain individuals.

Received: December 19, 2019 Revised: May 11, 2020

Accepted: August 6, 2020

$\triangle$ Correspondence: Kagan Kircaburun, MA

International Gaming Research Unit, Psychology Department, Nottingham

Trent University, 23 Shakespeare Street Nottingham, NG1 4FQ UK

Tel: +44738 433 3937, Fax: +441159418418

E-mail: kagan.kircaburun2019@my.ntu.ac.uk

(c) This is an Open Access article distributed under the terms of the Creative Commons Attribution Non-Commercial License (https://creativecommons.org/licenses/by$\mathrm{nc} / 4.0$ ) which permits unrestricted non-commercial use, distribution, and reproduction in any medium, provided the original work is properly cited.
Currently, an average of five billion YouTube videos are watched per day and YouTube has become one of the most popular social media platforms. ${ }^{1}$ YouTube is now as big as Facebook with over 1.8 billion monthly logged-in users. ${ }^{2}$ Although YouTube is a normal activity, a small minority of its users appear to engage in excessive and/or uncontrolled use and are adversely affected by it. Possible problematic use of YouTube (e.g., associated with addictive-like symptoms and negative consequences) has not received much attention among researchers, although a small number of studies have shown YouTube to bear the potential to become uncontrolled and problematic for a subgroup of users. ${ }^{3-6}$ Problematic YouTube use (PYU) is characterized by being preoccupied with YouTube, having a strong motivation to use YouTube, and spending excessive time on 
YouTube leading to impairments in social, personal and/or professional life, as well as psychological health and wellbeing.? The aforementioned studies having explored the correlates of problematic YouTube use (PYU) mainly focused on personality traits, motivations, gratifications, and content inclinations. ${ }^{3-6}$ These studies associated PYU with entertainment motives, specific content inclinations (e.g., algorithm-generated content chaining), social anxiety, and social gratifications.

To date, there is little empirically known regarding the potentially problematic consequences of a specific YouTube-related activity that has gained popularity in the past few years (i.e., "mukbang" watching). Mukbang originated in South Korea and is a combination of the Korean words "eating" ('meokneun') and "broadcast" ('bangsong'). ${ }^{8}$ A mukbang is therefore an "eating broadcast" where a mukbanger or broadcast jockey (the individual in the broadcast) eats various foods in front of the camera while interacting with viewers. ${ }^{9}$ Mukbangers eat messy foods while slurping, chomping, and displaying bad table manners. The origin of mukbang can be traced back to 2008 in South Korea with Afreeca television broadcasts, ${ }^{10}$ although its popularity skyrocketed across many regions worldwide after being introduced to western countries in 2015 when a popular American YouTube star uploaded a video commenting on Korean mukbangs. ${ }^{11}$ Since then, the number of mukbangers and their viewers has grown very fast worldwide, with popular mukbangers having millions of followers and their videos being watched by tens of thousands of viewers in very short periods of time. ${ }^{11}$ Mukbang is now watched by significant numbers of individuals via social networking sites (Instagram, YouTube, Twitch, online television, etc.), attracting many viewers on different types of mukbang. ${ }^{10}$

According to the compensatory internet use model within the behavioral addiction framework, vulnerable individuals are susceptible to using the internet in order to compensate unattained needs via specific online activities, such as playing videogames or interacting on social network sites. ${ }^{12}$ With facilitation provided by the internet and its accessibility, various types of problematic online behaviors emerged, and the misuse of information and communication technologies (ICTs) is now considered a worldwide public health issue by the World Health Organization. ${ }^{13}$ For instance, the problematic and uncontrolled use of video gaming, pornography, online gambling, and social netwotking sites have been described as specific maladaptive coping strategies engaged in to deal with unpleasent feelings and/or to compensate real-life unmet needs. ${ }^{14}$ Empirical studies have consistently highlighted associations between depression and loneliness and the problematic (e.g., excessive) involvement in various types of online activities such as social networking (e.g., Facebook use), pornography use, and bingewatching television series. ${ }^{15-20}$
Eating disorders have become more common in recent decades especially in combination with obesity. ${ }^{21}$ The total prevalence of lifetime eating disorders among U.S. adults has been reported as almost $2 \%$ and emerging adults appear to be more at risk of disordered eating compared to older age groups. ${ }^{22} \mathrm{~A}$ recent cross-sectional survey comprising a self-selected sample of emerging adults from different faculties of a Turkish university found that $10 \%$ of the sample was classed as being at high risk for having an eating disorder. ${ }^{23}$ While young females account for the majority of individuals with anorexia and bulimia nervosa, males and females are almost equally at risk for having binge eating disorder. ${ }^{21}$

It is not surprising that those who love food and/or who are addicted to food may use online platforms for food-related content. For instance, those who love food but do not want to suffer the negative consequences of excessive eating satisfy their needs by watching mukbang, which enables them to experience vicarious eating and satiation. ${ }^{24}$ Those who have different eating disorders (e.g., anorexia nervosa, binge eating) watch mukbang to overcome their problems for eating and food consumption, while some hospital patients who are unable to eat their desired food (e.g., unhealthy fast food) fulfill their eating urges by watching mukbang. ${ }^{24}$ In the present study, excessive and problematic mukbang watching is viewed within the theoretical framework of behavioral addiction. ${ }^{25}$ Consequently, successful attempts to compensate different offline eating needs by watching mukbang in social media platforms is likely to lead to repeated use of these activities, and to result in excessive (and in some cases problematic or addictive) mukbang watching. To date, there is only one study investigated problematic mukbang watching via examining different profiles of this behavior. ${ }^{26}$ The authors concluded that a minority of the participants could be labelled as high endorsement group (i.e., problematic mukbang watchers).

Watching mukbang can fulfill social gratifications for some of its users with its facilitation of communicating with the mukbangers and other viewers, ${ }^{10}$ and it is well established that compensating social needs via using specific online applications is associated with problematic use. ${ }^{3,27}$ In fact, mukbang has been suggested as representing a new form of social eating. ${ }^{11}$ Moreover, it can be argued that watching mukbang can fulfill social gratifications via the connection and affective bonding with mukbangers or other invividuals watching mukbang. From such a perspective, attachment towards watching mukbang could be even stronger for viewers following and interacting with mukbangers who reinforce them at the interpersonal and affective level. ${ }^{28}$ Indeed, it has been suggested that one of the main reasons for the appeal of this activity is related to the communication between broadcasters and their audiences. ${ }^{29} \mathrm{Con}$ sequently, problematic (e.g., addictive) mukbang watching could 
constitute another maladaptive coping strategy used to fullfil unmet offline social needs and deal with negative feelings (e.g., loneliness, depression).

Although viewers can watch mukbang using different online platforms (e.g., several social media sites, online broadcasting channels), mukbang watching is largely facilitated by YouTube in which viewers can interact with videos and live streams using comments and the like/dislike options. Past research has suggested that such structural interactive features (such as liking and/or commenting on others' posts, watching live streams) provided by YouTube increases its addictive potential, thus promoting problematic use. ${ }^{30,31}$ Given that YouTube is one of the most popular and unique platforms allowing for video content creation and viewing, ${ }^{2,3}$ it constitutes the ideal social networking site when it comes to conducting research on the mukbang phenomenon. Consequently, it was expected that individuals would widely use YouTube to watch mukbang and that PMW would be positively related to PYU.

Theoretically anchored within the compensatory usage of the internet theory, ${ }^{12}$ the present study tested whether PMW mediates the relationship between known psychosocial risk factors of problematic online behaviors (depression, loneliness) and PYU among a sample of mukbang viewers. While constructing the research model, the temporal precedence of the variables according to the theoretical rationale was taken into account. ${ }^{32}$ Depression and loneliness were included as the distal predictors postulated to promote compensatory usage of YouTube. Furthermore, it was postulated that depression and loneliness would predict PMW and PYU, and that PMW would mediate the relationship between these psychosocial risk factors and PYU, YouTube being the most popular platform for broadcasting and viewing mukbang. It was hypothesized that those who were depressed and lonely would engage in excessive mukbang watching via using YouTube in order to alleviate negative feelings. Moreover, because gender is known to influence the type of online activities favored (e.g., males prefer online gaming and females prefer social network sites), ${ }^{14,33}$ this variable was taken into account in the present study (i.e., models were computed for the whole sample and for males and females separately).

\section{METHODS}

\section{Participants and procedure}

Participants were Turkish mukbang viewers who completed an online survey. The survey was promoted on different online courses of a distance learning centre at a private university. Students had to acknowledge that participation in the study was completely voluntary and would not affect their grades nor would they get a compensation for participation. It was also emphasized that information regarding participants' identity would be completely confidential [e.g., no internet protocol (IP) address were recorded] and collected data would only be used for scientific purposes. A total of 1,204 students began the survey and 604 of completed it. To be included in the study, participants had to be mukbang viewers (i.e., watched mukbang videos at least once in their lifetime) and to have completed all survey items. Of these, 217 were mukbang watchers (watched mukbang at least once before) whose ages ranged between 18 and 33 years $\left(M_{\text {age }}=20.58\right.$ years, $S_{\text {age }}=1.88 ; 63 \%$ female). Those who indicated that they have never watched a mukbang before were excluded from the study ( $n=387)$. Participants first answered a demographic questionnaire that included items regarding their gender, age, YouTube use (frequency), and mukbang watching (frequency). Next, participants completed items assessing problematic YouTube use (this scale was adapted from the Bergen Facebook Addiction Scale $^{34}$ ), problematic mukbang watching (Mukbang Addiction Scale $^{26}$ ), depression (Short Happiness-Depression Scale ${ }^{35}$ ), and loneliness (UCLA- Loneliness Scale-Short Form ${ }^{36}$ ). Informed consent was provided by all participants and participation in the study was voluntary and anonymous. Ethical approval for the study was received from the research team's university's ethics committee, and complied with the Declaration of Helsinki (IRB approval number=2019/7).

\section{Measures}

\section{Problematic YouTube Use Scale (PYUS)}

The PYUS was the modified version of the Bergen Facebook Addiction Scale (BFAS; ${ }^{34}$ ) designed to assess problematic use of YouTube based on the addiction components proposed by Griffiths. ${ }^{25}$ This scale was developed after the BFAS by replacing for each item the word "Facebook" with "YouTube." It comprises six items (e.g., "How often in the past year have you used YouTube so much that it has had a negative impact on your job/studies?") assessing six features associated with addictive behaviors (i.e., salience, conflict, withdrawal, mood modification, tolerance, and relapse) scored on a 5-point Likert scale from "very rarely" to "very often." Structural validity of this adapted version of the BFAS was established in the present study by carring out confirmatory factor analyses (CFAs). Goodness of fit indices with the PYUS indicated good fit to the data $\left\{\chi^{2}\right\}$ $\mathrm{df}=1.26$, RMSEA=0.04 [CI 90\% $(0.00,0.10)]$, GFI=0.99, CFI= $1.00\}$ after modification covariances were used between Item 1 and Item 2 , and Item 2 and Item 3 as suggested. ${ }^{37}$ The reliability coefficient of the original scale and Turkish adaptation of the BFAS were both very good ( 0.83 and 0.83 respectively). ${ }^{34,38}$ The composite reliability score (CRS) alpha was very good in the present sample $(\alpha=0.86)$. 


\section{Mukbang Addiction Scale (MAS ${ }^{26}$ )}

The unidimensional MAS comprises six items (e.g., "How often in the past year have you spent a lot of time thinking about mukbang or planned watching mukbang?") and assesses problematic (i.e., addictive) mukbang watching on a five-point Likert scale from "very rarely" to "very often." The reliability coefficient of the MAS was excellent (0.95) in the original study. ${ }^{26}$ The CRS coefficient was also excellent in the present study $(\alpha=0.92)$.

\section{Short Depression-Happiness Scale $\left(\right.$ SDHS $^{35}$ )}

The original form of the SDHS comprises six items on a 4-point Likert scale from "never" to "often" and assesses subjective states of depression and happiness. ${ }^{35}$ However, the Turkish validation study suggested good psychometric properties for a two-dimension structure with three items assessing depression (e.g., "I felt that life was meaningless") and three items assessing happiness. ${ }^{39}$ The present study only used the three depression items. The reliability coefficient of the original SDHS and Turkish adaptation were 0.92 and 0.75 respectively. ${ }^{35,39}$ The CRS coefficient was very good in the present study $(\alpha=0.86)$.

\section{UCLA- Loneliness Scale-Short Form (ULS-4 ${ }^{36}$ )}

The unidimensional ULS-4 comprises four items (e.g., "People are around me but not with me") and assesses perceived feeling of loneliness on a 4-point Likert scale from "never" to "often." The reliability coefficient of the original ULS-4 and Turkish adaptation were 0.75 and 0.58 respectively. ${ }^{36,40}$ The CRS coefficient was good in the present study $(\alpha=0.74)$

\section{Statistical analysis}

All statistical analyses were carried out using SPSS 23 (IBM Corp., Armonk, NY, USA) and AMOS 23 (IBM Corp.). First, CFA was used to evaluate the factor structure of the PYUS. In order to determine goodness of fit of the CFA, root mean square residuals (RMSEA), standardized root mean square residuals (SRMR), comparative fit index (CFI), and goodness of fit index (GFI) were utilized. According to $\mathrm{Hu}$ and Bentler, ${ }^{41}$ RMSEA and SRMR lower than 0.05 is good and RMSEA and SRMR lower than 0.08 is adequate; CFI and GFI higher than
0.95 is good and CFI and GFI higher than 0.90 is acceptable. Frequency and descriptive statistics were computed with regard to gender, age, YouTube use, and mukbang watching. Following this, Pearson's correlation and t-tests were applied to examine the correlation coefficients between PYU, PMW, depression, and loneliness, and significance of the score differences between genders. Finally, path analysis was conducted in order to examine possible mediating role of study variables using a saturated model. ${ }^{37}$ More specifically, depression and loneliness were included as independent variables, PMW as the mediator, and PYU as the outcome variable into the model. Path analysis was carried out using maximum likelihood discrepancy with 5,000 bootstrapped samples and $95 \%$ biascorrected confidence intervals.

\section{RESULTS}

\section{Descriptive statistics}

Mean scores, standard deviations, and standardized regression weights of PYUS items are presented in Table 1. Mean scores and standard deviations of the main study variables

Table 2. Pearson's correlation coefficients, and descriptives of the study variables

\begin{tabular}{lcccccc}
\hline & 1 & 2 & 3 & 4 & 5 & 6 \\
\hline 1. PYU & - & & & & & \\
2. PMW & $0.48^{\ddagger}$ & - & & & & \\
3. Depression & $0.31^{\ddagger}$ & 0.11 & - & & & \\
4. Loneliness & 0.13 & $0.22^{\dagger}$ & $0.29^{\ddagger}$ & - & & \\
5. YouTube use & $0.37^{\ddagger}$ & 0.08 & -0.02 & $-0.15^{*}$ & - & \\
6. Mukbang & $0.22^{\dagger}$ & $0.44^{\ddagger}$ & 0.03 & $0.15^{*}$ & $0.27^{\ddagger}$ & - \\
$\quad$ watching & & & & & & \\
Mean & 2.16 & 1.47 & 2.24 & 2.05 & 2.23 & 0.71 \\
SD & 1.00 & 0.82 & 1.03 & 0.66 & 1.35 & 0.97 \\
Range & $1-5$ & $1-5$ & $1-4$ & $1-4$ & $0-5$ & $0-5$ \\
\hline
\end{tabular}

${ }^{*} \mathrm{p}<0.05,{ }^{\mathrm{p}} \mathrm{p}<0.01,{ }^{\ddagger} \mathrm{p}<0.001$. PYU: problematic YouTube use was assessed using the Problematic YouTube Use Scale, PMW: problematic mukbang watching was assessed using the Mukbang Addiction Scale, YouTube use: frequency of daily time spent using YouTube, Mukbang watching: frequency of daily time spent watching mukbang, SD: standard deviation

Table 1. Mean scores, standard deviations, and standardized regression wieghts of the items on the Problematic YouTube Use Scale

\begin{tabular}{lcc}
\hline \multicolumn{1}{c}{ How often during the last year have you ... } & Mean scores (SD) & Standardized regression weights \\
\hline Spent a lot of time thinking about YouTube or planned use of YouTube? & $2.41(1.21)$ & 0.60 \\
Felt an urge to use YouTube more and more? & $2.34(1.25)$ & 0.72 \\
Used YouTube in order to forget about personal problems? & $2.52(1.35)$ & 0.59 \\
Tried to cut down on the use of YouTube without success? & $1.89(1.16)$ & 0.85 \\
Become restless or troubled if you have been prohibited from using YouTube? & $1.86(1.17)$ & 0.90 \\
Used YouTube so much that it has had a negative impact on your job/studies? & $1.95(1.19)$ & 0.87 \\
\hline
\end{tabular}

SD: standard deviation 
are provided in Table 2. With regard to YouTube use, 36\% of the participants indicated using it less than one hour daily, $29 \%$ between one and two hours, $17 \%$ between two and three hours, 9\% between three and four hours, and 10\% more than four hours. With regard to mukbang watching, $91 \%$ of the participants indicated watching mukbang less than one hour daily, $4 \%$ between one and two hours, $2 \%$ between two and three hours, $1 \%$ between three and four hours, and $2 \%$ more than four hours. On average, two-thirds of the participants used YouTube more than one hour a day, whereas only $9 \%$ indicated watching mukbang more than one hour every day.

\section{Correlation analyses and independent samples t-tests}

Pearson's correlation test (Table 2) showed that PYU was moderately correlated with PMW ( $\mathrm{r}=0.48, \mathrm{p}<0.001)$, frequency of YouTube use $(r=0.37, p<0.001)$, and depression $(r=0.31$, $\mathrm{p}<0.001$ ), and weakly correlated with frequency of mukbang watching $(\mathrm{r}=0.22, \mathrm{p}<0.001)$. Loneliness was not correlated with PYU. PMW was moderately correlated with frequency of mukbang watching $(\mathrm{r}=0.44, \mathrm{p}<0.001)$ and weakly with loneliness $(\mathrm{r}=0.22, \mathrm{p}<0.01)$. Depression and frequency of Youtube use were not correlated with PMW. In order to examine the significance of the score differences between genders, independent samples t-tests were utilized (Table 3 ). Males were found to have a higher level of PYU $[\mathrm{t}(217)=-2.09, \mathrm{p}=0.04, \mathrm{df}=215]$ and PMW $[\mathrm{t}(217)=-3.39, \mathrm{p}=0.001, \mathrm{df}=215]$. There were no gender differences for depression $[\mathrm{t}(217)=1.46, \mathrm{p}=0.15, \mathrm{df}=$ 215] and loneliness [ $t(217)=0.68, \mathrm{p}=0.50, \mathrm{df}=215]$.

\section{Mediation analyses}

A saturated model, in which all fit indices had perfect values and with no modification indices, was used to evaluate hypothesized model (Figure 1). This was expected given the present study used path analysis but not structural equation modeling. Mediation analyses showed that PMW was associated with both loneliness and PYU. However, this indirect effect of loneliness on PYU via PMW did not lead to a significant total effect. Loneliness was not related to PYU. On the other hand, depression was directly associated with PYU [ $\beta=$ $0.26, \mathrm{p}<0.001$ CI 95\% $(0.15,0.38)]$. Depression was not associated with PMW in the path analysis (Table 4). Therefore, PMW did not mediate the relationship between depression and PYU. Despite the significant differences on PMW and PYU scores between females and males, there were no significant gender differences in direct and indirect associations in the path analysis (not depicted in the table or figure), indicating that the paths among the variables were invariant across both sexes.
Table 3. Comparison of the scores of study variables (t-test) between females and males

\begin{tabular}{lcccc}
\hline & $\begin{array}{c}\text { Females } \\
(\mathrm{N}=136)\end{array}$ & $\begin{array}{c}\text { Males } \\
(\mathrm{N}=81)\end{array}$ & t-test & Cohen's d \\
\hline $\begin{array}{l}\text { Problematic YouTube } \\
\text { use }\end{array}$ & $2.05(0.99)$ & $2.34(1.00)$ & $-2.09^{*}$ & 0.29 \\
$\begin{array}{l}\text { Problematic mukbang } \\
\text { watching }\end{array}$ & & & \\
$\begin{array}{l}\text { Depression } \\
\text { Loneliness }\end{array}$ & $2.31(0.67)$ & $1.71(0.98)$ & $-3.39^{\dagger}$ & 0.45 \\
\hline
\end{tabular}

Mean (SD). ${ }^{*} \mathrm{p}<0.05,{ }^{\dagger} \mathrm{p}<0.01 . \mathrm{SD}$ : standard deviation

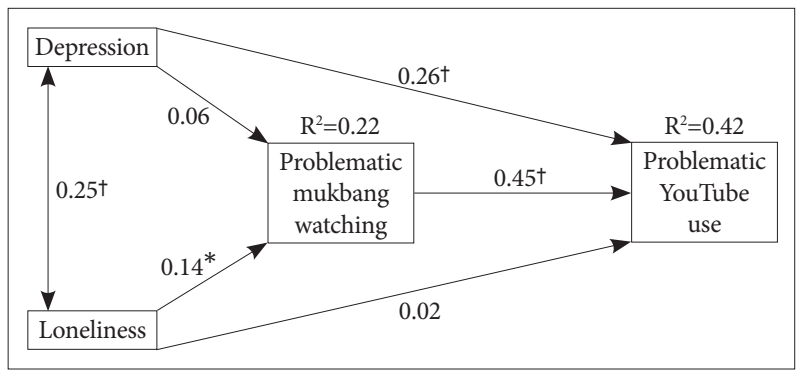

Figure 1. Results of path analyses with mediation model among total sample, males, and females. For clarity purposes, control variables (frequency of YouTube use and frequency of mukbang watching) were not depicted in the figure. In the model, frequency of YouTube use and mukbang watching were adjusted for PMW and PYU. Frequency of YouTube use was positively related to PYU $(\beta=0.37 ; p<0.001)$, while frequency of mukbang watching was positively related to PMW $(\beta=0.42 ; p<0.001)$. ${ }^{*} p<0.05$, ${ }^{\dagger} p<0.001$. PMW: problematic mukbang watching, PYU: problematic YouTube use.

Table 4. Standardized total, direct, and indirect effects of predictor variables on the outcome variable

\begin{tabular}{|c|c|c|}
\hline & $\beta$ & $\begin{array}{c}\text { Standard } \\
\text { error }\end{array}$ \\
\hline Depression $\rightarrow$ PYU (total effect) & $0.29^{\dagger}$ & 0.06 \\
\hline$\rightarrow$ PYU (direct effect) & $0.26^{\dagger}$ & 0.06 \\
\hline$\rightarrow$ PMW $\rightarrow$ PYU (indirect effect) & 0.03 & 0.03 \\
\hline Loneliness $\rightarrow$ PYU (total effect) & 0.09 & 0.06 \\
\hline$\rightarrow$ PYU (direct effect) & 0.02 & 0.05 \\
\hline$\rightarrow$ PMW $\rightarrow$ PYU (indirect effect) & $0.06^{*}$ & 0.03 \\
\hline
\end{tabular}

${ }^{*} \mathrm{p}<0.05,{ }^{\dagger} \mathrm{p}<0.001$. PYU: problematic YouTube use, PMW: problematic mukbang watching

\section{DISCUSSION}

The present study tested whether problematic mukbang watching (PMW) can be conceptualized-similar to other potentially problematic online activities (e.g., online gaming, cybersex)-as a maladaptive coping strategy. To the authors' knowledge, the present study is the first empirical investigation of PMW. It was found that depression and PMW were positively related to PYU. Loneliness was positively associated with PMW. 
The study's findings suggest that mukbang watching might constitute a dysfunctional coping mechanism for some individuals, especially among individuals displaying high loneliness. The present study failed to identify PMW as a significant mediator between depression and PYU. PMW was moderately and positively associated with PYU, but not with depression. In contrast, PMW was positively and directly associated with loneliness. In fact, the direct relationship between loneliness and PMW found in the present study suggests that PMW is more likely to be engaged in to fullfill unattained social needs (and thus to cope with loneliness) than to compensate a depressive mood per se. Mukbang enthusiasts can thus improve their feelings of social connectedness by watching mukbang and interacting with the content creators and viewers via a common interest, which is susceptible to alleviating their perceived feeling of loneliness. Finally, the positive relationship observed between PMW and PYU was expected. This is because YouTube is one of the most popular social media platforms that allows its users to create or view live streams and videos and to simultaneously interact with content creators and other viewers via comments, facilitating and attracting mukbang creators and viewers to meet and interact with each other.

Depression was positively associated with PYU. This finding is consistent with the literature reporting that elevated depression is related to higher problematic use of technological platforms. ${ }^{16,39,42}$ For example, past research has shown that depressed individuals are more prone to boredom and tend to use smartphones as a form of maladaptive coping. ${ }^{43}$ Similarly, it has also been shown that depressed individuals engage in problematic technology use to avoid or mitigate ruminative thoughts. ${ }^{44}$ Other research suggests that the relationship between depression and problematic use of technology is mediated by specific psychological factors such as distress tolerance and mindful traits. ${ }^{45}$ Further research should therefore consider the potential psychological factors that could account for the relationships observed in the present study (e.g., ruminations, mindfulness, emotion dysregulation).

Unexpectedly, loneliness was not associated with PYU in the present study. This finding conflicts with extant research demonstrating an association between loneliness and problematic use of technological platforms, ${ }^{15,46,47}$ suggesting that solitary individuals preferentially use online platforms to obtain social gratifications via interpersonal exchanges. ${ }^{48}$ However, the present study was conducted among a very specific sample of YouTube users (i.e., those watching mukbangs). Therefore it is perhaps unsurprising that for these individuals, loneliness is specifically related to mukbang watching, and not to YouTube use more generally. Such result supports the need to delineate the broad (and potentially deceptive) concepts such as 'YouTube Addiction'. Indeed, YouTube can be used for very heterogeneous purposes (e.g., broadcasting video games, watching specific YouTube channels, streaming live events), and the consequences and risk factors associated to these different use probably diverge, even if further studies are necessary to ascertain this claim.

It is also worth speculating on the factors that might explain the relationships observed in the present study. Although not directly assessed in the study, it is possible that specific motives related to social bonds or sexual fantasy promote excessive involvement in watching mukbang. Alternatively, it is also possible that mukbang watching is more prevalent among individuals presenting with eating disorder symptoms. For instance, individuals with bulimia and/or binge-eating disorders might engage in mukbang watching in order to perceive binge-eating massive meals as a normal or even healthy behavior. ${ }^{49}$ Furthermore, it cannot be excluded that for some individuals, excessive mukbang watching may constitute a potential addictivelike behavior. Indeed, excessive problematic food intake is increasingly viewed as an addictive disorder, ${ }^{50}$ and mukbang viewing, similar to binge-eating episodes, may promote feelings of satisfaction and pleasure. However, studies limited to a symptom-based approach, such as the present one, are claimed by some to be insufficient to support the view that mukbang watching can be conceptualized as an addictive disorder. ${ }^{51,52}$

Some limitations of the study also need to be acknowledged. First, the study comprised a sample of self-selected Turkish university students, which limits the generalization of the findings. The study should therefore be replicated in samples from different countries and cultures. Second, the study was cross-sectional and based on self-reports, therefore the responses are susceptible to well-known biases (e.g., some participants might lack introspection or provide socially desirable answers) and nothing can be said regarding causality between the variables investigated. Thirdly, the sample was imbalanced in terms of gender, and further studies should be conducted to analyze gender effect in mukbang watching and its misuse. Fourth, despite the fact that the daily time spent using YouTube and watching mukbang were adjusted for in the model, there might be other potential confounding factors (e.g., eating disorders, demographic factors) that should be controlled for. Therefore, future studies should take other factors into account when investigating the relationships that were examined in the present study. Fifthly, although all participants have watched mukbang before, most of them were involved in mukbang watching to a mild extent. Future studies should recruit participants that engage in this behavior more regularly and frequently. Finally, the study was limited to a symptom-based approach and additional measures assessing potential underlying psychological dimensions (e.g., ruminative thinking, motives for using YouTube and watching mukbang) is required to better under- 
stand the processes involved. ${ }^{53}$ Along the same lines, further research should develop a scale that assesses the unique nature of mukbang watching (e.g., by relying on mixed qualitative and quantitative designs), rather than applying a confirmatory approach which consists in using criteria from other addictive disorders and applying them to emerging problematic behaviors (for an example in the context of problematic television series watching) ${ }^{18}$

Despite these limitations, this study contributes to understanding of the relationships between depression, loneliness, PMW, and PYU. This study showed that depression was positively associated with PYU, whereas loneliness was positively related to PMW. Furthermore, PMW was moderately associated with PYU. Crucially, the present study is the first to examine mukbang watching as a potential maladaptive coping and compensatory behavior. However, future studies should be conducted to further delineate the etiological factors involved and the uniqueness and similarities with other problematic online behaviors or eating disorders. ${ }^{54}$

\section{Acknowledgments}

Zsolt Demetrovics was supported by the Hungarian National Research, Development and Innovation Office (Grant number: K111938, KKP126835).

\section{Conflicts of Interest}

The authors have no potential conflicts of interest to disclose.

\section{Author Contributions}

Conceptualization: Kagan Kircaburun, Mark D. Griffiths, Zsolt Demetrovics. Data curation: Sabah Balta, Emrah Emirtekin. Formal analysis: Kagan Kircaburun, Şule Betül Tosuntaş. Writing—original draft: Kagan Kircaburun. Writing_review \& editing: Kagan Kircaburun, Mark D. Griffiths, Zsolt Demetrovics.

\section{ORCID iDs}

Kagan Kircaburun https://orcid.org/0000-0002-8678-9078

Sabah Balta https://orcid.org/0000-0002-7353-3110

Emrah Emirtekin https://orcid.org/0000-0002-3970-4406

Şule Betül Tosuntaş https://orcid.org/0000-0002-0731-6505

Zsolt Demetrovics https://orcid.org/0000-0001-5604-7551

Mark D. Griffiths https://orcid.org/0000-0001-8880-6524

\section{REFERENCES}

1. Aslam S. YouTube by the numbers: Stats, demographics \& fun facts; 2018. Available at: https://www.omnicoreagency.com/youtube-statistics/. Accessed April 1, 2019.

2. Gilbert B. YouTube now has over 1.8 billion users every month, within spitting distance of Facebook's 2 billion; 2018. Available at: https:// www.businessinsider.com/youtube-user-statistics-2018-5. Accessed April 1, 2019.

3. Balakrishnan J, Griffiths MD. Social media addiction: what is the role of content in YouTube? J Behav Addict 2017;6:364-377.

4. de Bérail P, Guillon M, Bungener C. The relations between YouTube addiction, social anxiety and parasocial relationships with YouTubers: a moderated-mediation model based on a cognitive-behavioral framework. Comput Human Behav 2019;99:190-204.

5. Klobas JE, McGill TJ, Moghavvemi S, Paramanathan T. Compulsive YouTube usage: a comparison of use motivation and personality effects.
Comput Human Behav 2018;87:129-139.

6. Klobas JE, McGill TJ, Moghavvemi S, Paramanathan T. Problematic and extensive YouTube use: first hand reports. Online Inform Rev 2019; 43:265-282.

7. Andreassen CS, Pallesen S. Social network site addiction-an overview. Curr Pharm Des 2014;20:4053-4061.

8. Lavelle D. Mukbang: is loneliness behind the craze for watching other people eating? The Guardian, November 5, 2018. Available at: https:// www.theguardian.com/food/shortcuts/2018/nov/05/mukbang-isloneliness-behind-the-craze-for-watching-other-people-eating. Accessed April 1, 2019.

9. Schwegler-Castañer A. At the intersection of thinness and overconsumption: the ambivalence of munching, crunching, and slurping on camera. Fem Media Stud 2018;18:782-785.

10. Hong S, Park S. Internet mukbang (foodcasting) in South Korea. In: Eleá I, Mikos L, Editors. Young and Creative: Digital Technologies Empowering Children in Everyday Life. Göteborg, Sweden: Nordicom, 2018, p.111-125.

11. McCarthy A. This korean food phenomenon is changing the internet; 2017. Available at: https://www.eater.com/2017/4/19/15349568/mukbang-videos-korean-youtube. Accessed April 1, 2019.

12. Kardefelt-Winther D. A conceptual and methodological critique of internet addiction research: towards a model of compensatory internet use. Comput Human Behav 2014;31:351-354.

13. World Health Organization. Public health implications of excessive use of the internet, computers, smartphones and similar electronic devices: Meeting report, Main Meeting Hall, Foundation for Promotion of Cancer Research, National Cancer Research Centre, Tokyo, Japan, 2729 August 2014. Geneva: World Health Organization; 2015.

14. Sindermann C, Sariyska R, Lachmann B, Brand M, Montag C. Associations between the dark triad of personality and unspecified/specific forms of internet-use disorder. J Behav Addict 2018;7:985-992.

15. Atroszko PA, Balcerowska JM, Bereznowski P, Biernatowska A, Pallesen S, Andreassen CS. Facebook addiction among Polish undergraduate students: validity of measurement and relationship with personality and well-being. Comput Human Behav 2018;85:329-338.

16. Błachnio A, Przepiórka A, Pantic I. Internet use, Facebook intrusion, and depression: results of a cross-sectional study. Eur Psychiatry 2015; 30:681-684.

17. Boudali M, Hamza M, Bourgou S, Jouini L, Charfi F, Belhadj A. Depression and anxiety among Tunisian medical students "binge viewers". Eur Psychiatry 2017;41:675-676.

18. Flayelle M, Canale N, Vögele C, Karila L, Maurage P, Billieux J. Assessing binge-watching behaviors: development and validation of the "Watching TV Series Motives" and "Binge-Watching Engagement and Symptoms" questionnaires. Comput Human Behav 2019;90:26-36.

19. Li JB, Mo PK, Lau JT, Su XF, Zhang X, Wu AM, et al. Online social networking addiction and depression: the results from a large-scale prospective cohort study in Chinese adolescents. J Behav Addict 2018;7: 686-696.

20. Philaretou AG, Mahfouz AY, Allen KR. Use of internet pornography and men's well-being. Int J Men Health 2005;4:149-169.

21. Schmidt U, Adan R, Böhm I, Campbell IC, Dingemans A, Ehrlich S, et al. Eating disorders: the big issue. Lancet Psychiatry 2016;3:313-315.

22. Udo T, Grilo CM. Prevalence and correlates of DSM-5-defined eating disorders in a nationally representative sample of US adults. Biol Psychiatry 2018;84:345-354.

23. Sanlier N, Yassibas E, Bilici S, Sahin G, Celik B. Does the rise in eating disorders lead to increasing risk of orthorexia nervosa? Correlations with gender, education, and body mass index. Ecol Food Nutr 2016;55: 266-278.

24. Kircaburun K, Harris A, Calado F, Griffiths MD. The psychology of mukbang watching: a scoping review of the academic and non-academic literature. Int J Ment Health Addict 2020 [Epub ahead of print].

25. Griffiths M. A 'components' model of addiction within a biopsychoso- 
cial framework. J Subst Use 2005;10:191-197.

26. Kircaburun K, Stavropoulos V, Harris A, Calado F, Emirtekin E, Griffiths MD. Development and validation of the Mukbang Addiction Scale. Int J Ment Health Addict 2020 [Epub ahead of print].

27. Zanetta-Dauriat F, Zermatten A, Billieux J, Thorens G, Bondolfi G, Zullino D, et al. Motivations to play specifically predict excessive involvement in Massively Multiplayer Online Role-Playing Games (MMORPGs): evidence through an online survey. Eur Addict Res 2011;17:185189.

28. Wijayanti N. Mukbang: A ludic way to have a meal. 2018. Available at: https://www.diggitmagazine.com/column/mukbang-ludic-way-havemeal. Accessed April 1, 2019.

29. Recktenwald D. Toward a transcription and analysis of live streaming on Twitch. J Pragmat 2017;115:68-81.

30. Griffiths MD. Adolescent social networking: how do social media operators facilitate habitual use? Educ Health 2018;36:66-69.

31. Kircaburun K, Griffiths MD. Problematic Instagram use: the role of perceived feeling of presence and escapism. Int J Ment Health Addict 2019;17:909-921.

32. Kline RB. The mediation myth. Basic Appl Soc Psychol 2015;37:202213.

33. Andreassen CS, Billieux J, Griffiths MD, Kuss DJ, Demetrovics Z, Mazzoni E, et al. The relationship between addictive use of social media and video games and symptoms of psychiatric disorders: a largescale cross-sectional study. Psychol Addict Behav 2016;30:252-262.

34. Andreassen CS, Torsheim T, Brunborg GS, Pallesen S. Development of a Facebook addiction scale. Psychol Rep 2012;110:501-517.

35. Joseph S, Linley PA, Harwood J, Lewis CA, McCollam P. Rapid assessment of well-being: the Short Depression-Happiness Scale (SDHS). Psychol Psychother 2004;77:463-478.

36. Hays RD, DiMatteo MR. A short-form measure of loneliness. J Pers Assess 1987;51:69-81.

37. Byrne BM. Structural Equation Modeling with AMOS: Basic Concepts, Applications, and Programming. London: Routledge; 2016.

38. Yurdagül C, Kircaburun K, Emirtekin E, Wang P, Griffiths MD. Psychopathological consequences related to problematic Instagram use among adolescents: the mediating role of body image dissatisfaction and moderating role of gender. Int J Ment Health Addict 2019 [Epub ahead of print].

39. Kircaburun K, Kokkinos CM, Demetrovics Z, Király O, Griffiths MD, Çolak TS. Problematic online behaviors among adolescents and emerging adults: associations between cyberbullying perpetration, problematic social media use and psychosocial factors. Int J Ment Health Addict 2019;17:891-908.

40. Eskin M. Adolescent loneliness, coping methods and the relationship of loneliness to suicidal behavior. Clin Psychiatry 2001;4:5-11.

41. Hu LT, Bentler PM. Cutoff criteria for fit indexes in covariance struc- tural analysis: conventional criteria versus new alternatives. Struct Equ Model 1999;6:1-55.

42. Kircaburun K, Griffiths MD, Billieux J. Trait emotional intelligence and problematic online behaviors among adolescents: the mediating role of mindfulness, rumination, and depression. Pers Individ Diff 2019; 139:208-213.

43. Elhai JD, Vasquez JK, Lustgarten SD, Levine JC, Hall BJ. Proneness to boredom mediates relationships between problematic smartphone use with depression and anxiety severity. Soc Sci Comput Rev 2018;36: 707-720.

44. Elhai JD, Tiamiyu M, Weeks J. Depression and social anxiety in relation to problematic smartphone use: the prominent role of rumination. Internet Res 2018;28:315-332.

45. Elhai JD, Levine JC, O’Brien KD, Armour C. Distress tolerance and mindfulness mediate relations between depression and anxiety sensitivity with problematic smartphone use. Comput Human Behav 2018; 84:477-484.

46. Kim JH. Psychological issues and problematic use of smartphone: ADHD's moderating role in the associations among loneliness, need for social assurance, need for immediate connection, and problematic use of smartphone. Comput Human Behav 2018;80:390-398.

47. Özdemir Y, Kuzucu Y, Ak Ş. Depression, loneliness and Internet addiction: How important is low self-control? Comput Human Behav 2014;34:284-290.

48. Ryan T, Chester A, Reece J, Xenos S. The uses and abuses of Facebook: a review of Facebook addiction. J Behav Addict 2014;3:133-148.

49. Kim M. Extreme eating: Are "mukbangs" helpful or hurtful to those with eating disorders. 2017. Available at: http://www.hcs.harvard. edu/ hcht/blog/eating-disorder. Accessed April 1, 2019.

50. Love T, Laier C, Brand M, Hatch L, Hajela R. Neuroscience of internet pornography addiction: a review and update. Behav Sci 2015;5:388433.

51. Billieux J, Schimmenti A, Khazaal Y, Maurage P, Heeren A. Are we overpathologizing everyday life? A tenable blueprint for behavioral addiction research. J Behav Addict 2015;4:119-123.

52. Starcevic V, Billieux J, Schimmenti A. Selfitis, selfie addiction, Twitteritis: Irresistible appeal of medical terminology for problematic behaviours in the digital age. Aust N Z J Psychiatry 2018;52:408-409.

53. Billieux J, Philippot P, Schmid C, Maurage P, de Mol J, Van der Linden M. Is dysfunctional use of the mobile phone a behavioural addiction? Confronting symptom-based versus process-based approaches. Clin Psychol Psychother 2015;22:460-468.

54. Kircaburun K, Yurdagül C, Kuss D, Emirtekin E, Griffiths MD. Problematic mukbang watching and its relationship to disordered eating and internet addiction: a pilot study among emerging adult mukbang watchers. Int J Ment Health Addict 2020 [Epub ahead of print]. 